\title{
Decreased Interleukin-4 Release from the Neurons of the Locus Coeruleus in Response to Immobilization Stress
}

\author{
Hyun-ju Lee, ${ }^{1}$ Hyun-Jung Park, ${ }^{1}$ Angela Starkweather, ${ }^{2}$ Kyungeh An, ${ }^{2}$ and Insop Shim ${ }^{1,2}$ \\ ${ }^{1}$ Acupuncture and Meridian Science Research Center, College of Oriental Medicine, Kyung Hee University, 26 Kyunghee-daero, \\ Dongdaemun-gu, Seoul 130-701, Republic of Korea \\ ${ }^{2}$ Department of Adult Health and Nursing Systems, School of Nursing, Virginia Commonwealth University, \\ Richmond, VA 23298-0567, USA \\ Correspondence should be addressed to Insop Shim; ishim@khu.ac.kr
}

Received 4 April 2015; Revised 2 July 2015; Accepted 17 December 2015

Academic Editor: Sun Wook Hwang

Copyright $\odot 2016$ Hyun-ju Lee et al. This is an open access article distributed under the Creative Commons Attribution License, which permits unrestricted use, distribution, and reproduction in any medium, provided the original work is properly cited.

It has been demonstrated that immobilization (IMO) stress affects neuroimmune systems followed by alterations of physiology and behavior. Interleukin-4 (IL-4), an anti-inflammatory cytokine, is known to regulate inflammation caused by immune challenge but the effect of IMO on modulation of IL- 4 expression in the brain has not been assessed yet. Here, it was demonstrated that IL- 4 was produced by noradrenergic neurons in the locus coeruleus (LC) of the brain and release of IL- 4 was reduced in response to IMO. It was observed that IMO groups were more anxious than nontreated groups. Acute IMO ( $2 \mathrm{~h} /$ day, once) stimulated secretion of plasma corticosterone and tyrosine hydroxylase (TH) in the LC whereas these increments were diminished in exposure to chronic stress ( $2 \mathrm{~h}$ /day, 21 consecutive days). Glucocorticoid receptor (GR), TH, and IL-4-expressing cells were localized in identical neurons of the LC, indicating that hypothalamic-pituitary-adrenal- (HPA-) axis and sympathetic-adrenal-medullary- (SAM-) axis might be involved in IL-4 secretion in the stress response. Accordingly, it was concluded that stress-induced decline of IL- 4 concentration from LC neurons may be related to anxiety-like behavior and an inverse relationship exists between IL- 4 secretion and HPA/SAMaxes activation.

\section{Introduction}

Stress induces neuroinflammation accompanied by altered production of neuropeptides and inflammatory cytokines in the central nervous system (CNS). Such modulation in the CNS affects endocrine and immune systems followed by behavioral changes [1-3]. Immobilization (IMO) is a severe stressor that triggers both physiological and behavioral responses.

An inflammatory process is developed by imbalanced release of pro- and anti-inflammatory cytokines in response to IMO. Interleukin-4 (IL-4) is an anti-inflammatory cytokine and has an ability to inhibit synthesis of IL- $1 \beta$, a proinflammatory cytokine, and upregulate the production of IL1 receptor antagonist $[4,5]$. The effect of stress on secretion of IL-4 in the periphery is highly controversial. It has been shown that serum IL-4 level was decreased [6], and not changed [7], or the number of airway IL-4 positive cells was increased [8] in various animal models of stress. Several human studies reported that social stress test and public speaking had no association with blood IL-4 concentration $[2,9,10]$. Stress-induced modification of IL- 4 release in the brain, however, has not been assessed fully. Th2 helper $\mathrm{T}$ lymphocytes are responsible for production of IL-4 in the periphery [11] and microglia are reported as a IL-4 secreting cell in the cortex of the brain [12], whereas IL-4 producing cells in the LC of the brain have not been identified yet.

Activation of the hypothalamic-pituitary-adrenal- (HPA-) and sympathetic-adrenal-medullary- (SAM-) axes is also a typical response induced by IMO. The final consequence of HPA-axis activation is increased corticosterone (CORT) release in the plasma [13-16]. The locus coeruleus (LC) is a stress-response brainstem and a major part of the SAMaxis for its role in regulating norepinephrine (NE) release. Secretion of NE and expression of tyrosine hydroxylase (TH), an enzyme involved in the synthesis of NE, are stimulated as a result of SAM-axis activation $[17,18]$. SAM-axis modulation 
by the HPA-axis occurs via projections of the LC to the stressrelated brain regions interconnected with the hypothalamus [19]. Anxiety-like behavior in the elevated plus maze (EPM) test was also reported in an IMO-administered animal group $[20,21]$. Several researches have shown that glucocorticoid influences IL-4 production and IL-4 signaling in vitro [22, 23]. It was also shown that injection of IL- 4 altered free radical processes evoked by stress [24]. Stress-induced involvement of IL-4 in HPA- and SAM-axes activation in vivo is not fully delineated yet, whereas the release of proinflammatory cytokines has been well established.

The purpose of this study was to assess the influence of acute and chronic IMO on IL- 4 concentrations and to identify the characteristics of IL-4 producing cells in the LC region of the brain. We also focused on the correlation of IL-4 secretion, anxiety-like behavior, and HPA-/SAM-axes activation in the stress response.

\section{Materials and Methods}

2.1. Animals. All the experimental procedures performed on the animals were conducted with the approval of the Ethics Committee of the Kyung Hee University (KHUAP(SE)-13041) and in accordance with the US National Institutes of Health (Guide for the Care and Use of Laboratory Animals, 8 th edition, revised 2011). Male Sprague-Dawley rats (Orient Animal Corp., Gyeonggi-do, Korea) aged 7 weeks (310-360 g) were housed under a 12-h light schedule with controlled temperature at $22^{\circ} \mathrm{C}$ and humidity. Animals had access to water and food ad libitum and were acclimated for 7 days prior to experiments. The experiments were performed according to the animal care guidelines of the NIH and Kyung Hee University Institutional Animal Care.

2.2. Immobilization Stress Procedure. The animals were randomly assigned to control, acute IMO, or chronic IMO groups. The acute IMO group was restrained for 2 hours once in a cone-shaped PVC which restricts forward, backward, and lateral movements. Chronic IMO was administered daily for 21 consecutive days.

2.3. Elevated Plus Maze (EPM) Test. After exposure to stress, the animals were immediately tested in the EPM. The EPM test was adapted from Walf and Frye [25] except that the animals were placed in the center of the maze facing one of the closed arms. The time spent on the open arms and the closed arms of the maze were video-taped and recorded for 5 min by S-MART program (Pan-Lab, Barcelona, Spain).

\subsection{Enzyme Linked Immunosorbent Assay (ELISA)}

2.4.1. Interleukin-4 (IL-4). After all stress procedures were done, the animals were deeply anesthetized with sodium pentobarbital ( $80 \mathrm{mg} / \mathrm{kg}$, administered i.p.) and the brains were immediately removed and sectioned in a coronal manner by using rodent brain matrix (ASI instruments Inc., MI, USA). The LC region of the brain was punched out on a cold plate and stored at $-70^{\circ} \mathrm{C}$ until the assay. The obtained tissue was thawed and homogenized in ice cold cell lysis buffer (Cell Signaling Technology Inc., Danvers, MA, USA) and centrifuged $\left(10,000 \times \mathrm{g}\right.$ at $4^{\circ} \mathrm{C}$ for $\left.30 \mathrm{~min}\right)$. Protein concentrations in homogenates were equalized $(1 \mu \mathrm{g} / \mu \mathrm{L})$ by Bradford assay. IL- 4 concentration in duplicate $100 \mu \mathrm{L}$ aliquots was assessed by ELISA kit according to the manufacturer's instructions (Promikine, Heidelberg, Germany).

2.4.2. Corticosterone (CORT). After exposure to the stress, the animals were anesthetized with sodium pentobarbital (80 mg/kg, administered i.p.) and cardiac blood was collected. The obtained sample was centrifuged $(10,000 \times \mathrm{g}$ at $4^{\circ} \mathrm{C}$ for $30 \mathrm{~min}$ ) and plasma was collected and then stored at $-70^{\circ} \mathrm{C}$ until the assay. Level of CORT in the plasma was analyzed by ELISA kits according to the manufacturer's instructions (Assay Designs, Ann Arbor, MI, USA).

2.4.3. Immunofluorescent Staining. Double immunofluorescence staining of IL-4 with TH, released from noradrenergic neuron in the LC [26], glial fibrillary acidic protein (GFAP), an astrocyte specific marker, and ionized calcium-binding adaptor protein-1 (Iba-1), a marker for microglia, was performed to identify IL-4 secreting cell in the LC.

To determine the role of the HPA- and SAM-axes in IL-4 secretion via the LC during the stress response, glucocorticoid receptor (GR), TH, and IL-4-expressing cells were also double stained. The rat brains were removed after transcardial perfusion with $4 \%$ solution of formaldehyde (Sigma-Aldrich St. Louis, MO, USA), then postfixed in the same fixative for 24 hours, and placed in PBS containing $20 \%$ of sucrose for $72 \mathrm{hr}$. Serial coronal sections were cut into $30 \mu \mathrm{m}$ thickness by using a cryostat microtome (CM 1850UV, Leica Microsystems Inc., Wetzlar, Germany) and the sections were processed as free-floating. The sections of the LC (bregma $-9.57 \mathrm{~mm}$ to $-9.99 \mathrm{~mm}$ ) were blocked with $10 \% \mathrm{v} / \mathrm{v}$ normal horse serum (Vector Laboratories, Inc., Burlingame, CA, USA) for $1 \mathrm{hr}$ at room temperature with constant agitation at $100 \mathrm{rpm}$. The sections were then rinsed in PBS followed by incubation in IL-4 mouse monoclonal IgG (diluted 1:25, Santa Cruz Biotechnology, Inc., Dallas, Texas, USA), TH rabbit monoclonal IgG (diluted 1:1000, Millipore, San Francisco, CA, USA), Iba-1 rabbit polyclonal IgG (diluted 1:200, Wako, Japan), GFAP rabbit polyclonal IgG (diluted 1:2000, Abcam, Cambridge, UK), or GR rabbit polyclonal IgG (diluted 1:50, Santa Cruz Biotechnology, Inc., Dallas, Texas, USA) for 48 hours at $4^{\circ} \mathrm{C}$ with constant agitation. Then, the sections were rinsed in PBS and subsequently incubated with horse anti-mouse conjugated to fluorescein isothiocyanate (FITC) (diluted 1:200, Vector Laboratories, Inc., Burlingame, CA, USA) or fluorescent Alexa Fluor 546 dye-labeled anti-rabbit IgG at room temperature for 2 hours with constant agitation. The sections were again rinsed in PBS, mounted onto slides, and cover-slipped with Vectashield mounting medium (Vector Laboratories, Inc., Burlingame, CA, USA). Samples were viewed by confocal microscope (LSM 510 Meta, Carl Zeiss Inc., Oberkochen, Germany). The density of immunopositive neurons in the $\mathrm{LC}$ region was 


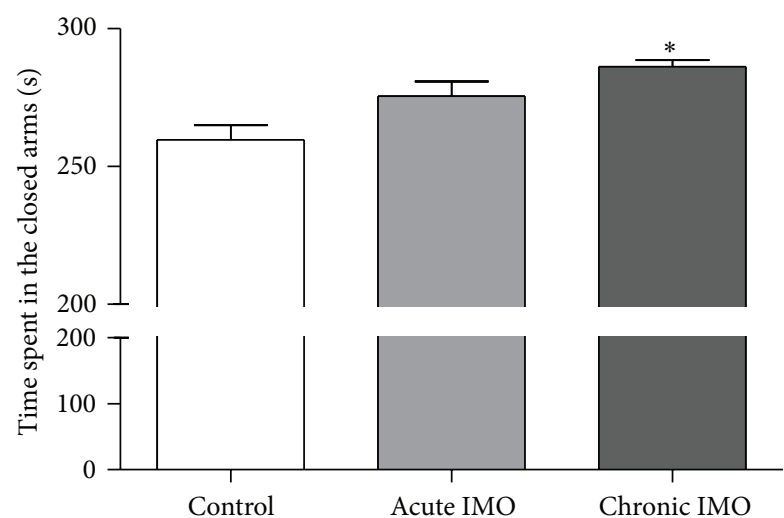

(a)

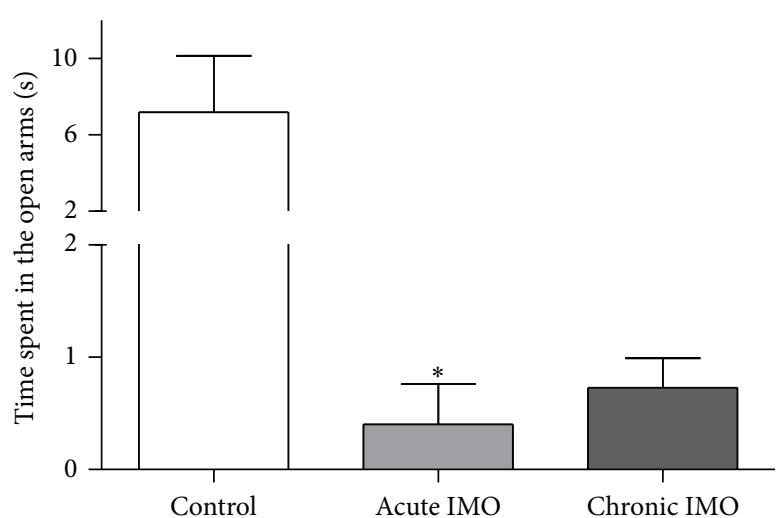

(b)

FIGURE 1: Mean ( \pm SEM) time spent in the closed arms and the open arms during EPM test for the acutely and chronically stressed and control rats. (a) Chronic IMO induced a significant increase in time spent on the closed arms. (b) Acute IMO led animals to stay for significantly less amount of time in the open arms. $(n=6 \text { per group })^{*} P<0.05$ versus control; ANOVA.

quantified according to Paxinos et al. [27] using the Scion image program (Scion Corp., MD, USA).

2.5. Statistics Analysis. The data were expressed as the mean \pm standard error of the mean (SEM). Comparisons among different groups were analyzed by one-way analysis of variance (ANOVA) followed by Scheffe's test as a post hoc test. All the statistical analyses were performed using SPSS (version 18.0., SPSS, Chicago, IL, USA). $P$ values below 0.05 were regarded as statistically significant.

\section{Results}

3.1. Elevated Plus Maze. The EPM test was performed to compare the anxiety level between stressed and control rats. The time spent on the closed arms $\left(F_{2,13}=6.9, P<0.05\right)$ and on the open arms $\left(F_{2,17}=4.9, P<0.05\right)$ was recorded during the 5 minutes of the test (Figure 1). The chronic IMO group showed significantly increased time spent on the closed arms $(P<0.05$; Figure $1(\mathrm{a}))$ and the acute IMO group had a less amount of time on the open arms $(P<0.05$; Figure 1(b)) than the control group.

\subsection{Enzyme Linked Immunosorbent Assay (ELISA)}

3.2.1. Interleukin-4 (IL-4). Concentration of IL-4 protein was assessed in the $100 \mu \mathrm{g}$ aliquot of the LC in the IMO-subjected and nontreated rats. IMO had an effect on the decrease of IL-4 secretion in the rat brain stem $\left(F_{2,12}=6.9, P<0.05\right.$; Figure 2). The rats under acute IMO showed significantly greater reduction in the release of IL-4 protein compared to the control group $(P<0.05)$.

3.2.2. Corticosterone (CORT). Plasma CORT level was analyzed in the control, acutely and chronically stressed groups $\left(F_{2,24}=6.6, P<0.05\right)$. The rats subjected to acute IMO revealed a significantly higher increment of CORT compared to controls $(P<0.05$; Figure 3$)$. In contrast, reduced release

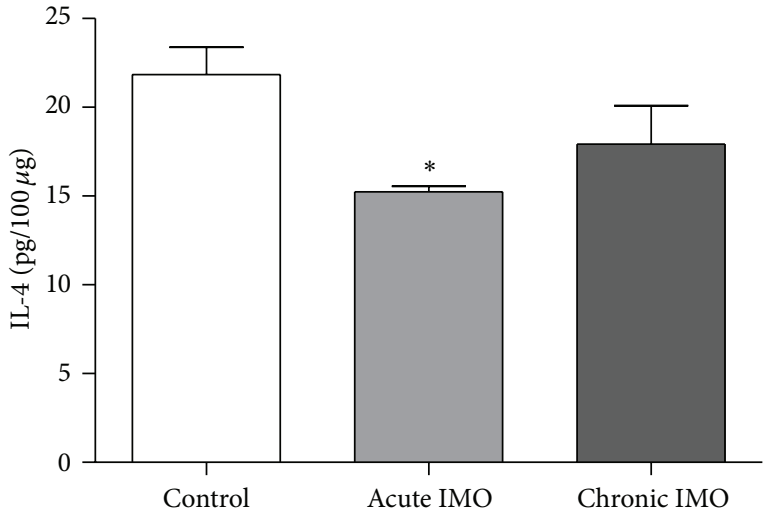

Figure 2: Mean ( \pm SEM) IL-4 protein level in the LC of the acutely and chronically stressed and control rats. Expression of IL-4 was significantly decreased in the acutely stressed group. $(n=6$ per group) ${ }^{*} P<0.05$ versus control; ANOVA.

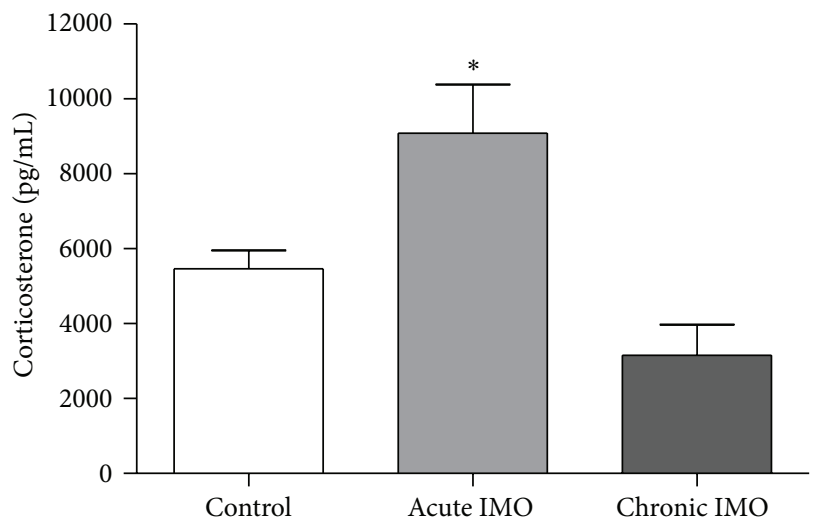

FIgure 3: Mean ( \pm SEM) CORT level in the plasma of the control, acute, and chronic IMO-submitted rats. Acute IMO significantly increased plasma CORT whereas chronic IMO induced reduction of CORT release. $\left(n=8\right.$ per group) ${ }^{*} P<0.05$ versus control; ANOVA. 
of CORT was showed in the chronic IMO group compared with the control group.

3.2.3. Identification of IL-4-Producing Cells in the LC. Immunohistochemical analysis was used to characterize IL-4 releasing cells in the brain stem. Double staining revealed that IL-4-immunoreactive cells (Figures 4(a) and 4(d)) and THpositive cells (Figures 4(b) and 4(e)) were colocalized in the LC (Figures 4(c) and 4(f)). IL-4 producing cells were not merged with immune-labeling of GFAP (an astrocyte specific marker) or Iba-1 (a marker for microglia) (Figures 4(i) and $4(1)$, resp.).

3.2.4. Expression of GR. Immunofluorescent analysis was used to further explore the localization of GR and IL-4 in the LC. Double staining showed that IL-4 (Figures 5(a) and 5(d)) and GR (Figures 5(b) and 5(e)) were localized in different compartments of the identical cells (Figures 5(c) and 5(f)), which are neurons, of the LC.

3.2.5. Expression of $T H$. Immunofluorescence was performed to quantify the expression of the TH in the LC of the controls and the stressed rats $\left(F_{2,10}=43.2, P<0.001\right)$. Density of TH was considerably increased in the acute IMO group compared to control group $(P<0.001$; Figure 6$)$, but no significant alteration was observed in the chronic IMO group.

\section{Discussion}

It has been reported that IMO-induced stress had an inhibitory effect on IL-4 release in peripheral tissues of human and rat [28-30]. Lipopolysaccharide (LPS) had a similar effect of stress in respect to inducing immunomodulation characterized by increased production of proinflammatory cytokines. IL-4 protein level was considerably decreased in the LPS-treated rat brain and IL- $4^{-/-}$mice were more vulnerable to LPS than wild type $[4,31,32]$. In this study, it was demonstrated that the production of IL-4 protein in the LC region of the brain was significantly decreased in the acutely stressed group. Although it has been reported that there was no significant change or elevated release of peripheral IL4 in stress responses $[8,33,34]$, these controversial data indicated that stress-induced alteration of IL-4 secretion may differ in a tissue-specific manner and further studies should be demonstrated. Taken together, these findings suggest that stress has an inhibitory effect on IL-4 production in the brain.

It has been reported that IL-4 is released from microglia in the cortex of the brain [12]. Also an in vitro study reported glia as the cell source of IL-4 in the brain [4]. In this study, however, IL-4 was produced from the TH-producing cells identified as noradrenergic neurons [26] of the LC. Neither astrocyte nor microglia released IL-4 in the LC region of the brain. The data is the first to identify IL- 4 expressing cells in the LC suggesting that IL-4 is produced by different type of cells in a site-specific manner in the brain. Further research is required to demonstrate identification of IL-4-secreting cells in other brain regions besides the cortex and the LC.
Previous work has shown that restraint stress-submitted groups were more anxious than nontreated groups [3537] and increment of corticosterone had an anxiolytic-like effect in animal model [38]. Central and peripheral IL4 concentration had an effect of suppressing LPS-induced sickness behavior $[39,40]$ and IL- ${ }^{-/-}$mice exhibited more anxious behavior compared to wild type [41]. It has been reported that CORT had a suppressive effect on IL-4 protein production and signaling in in vitro and in vivo studies $[22,23,42,43]$. It was observed that IMO stressed rats had significantly increased anxiety and reduced IL-4 protein level in the brain. Reduction of IL-4 protein release from LC was accompanied by an increase of circulating CORT level in acute stress response. GR is known to be abundantly expressed in the LC neurons [44] and it was confirmed that GR and IL-4 were localized in the identical neurons of LC in this study. Consequently the data suggests that acute IMOinduced hypercorticism may contribute to downregulation of IL-4 production in the LC and this decrement of IL-4 level leads to behavioral change.

Accumulating evidence suggests that a single exposure of stress leads to a significant increase in circulating CORT level and nuclear GR intensity and activity [45] as a result of HPAaxis activation $[13,14,46]$. It has been reported, however, that chronic exposure of homotypic stress induces hypocorticism $[45,47-50]$. Also increment of nuclear GR intensity and activity was abolished in the chronic restraint stressed group [45]. In the present study, CORT concentration was increased in the acute IMO group, whereas chronic stressed rats had decreased CORT level compared with controls. Taken together, the findings suggest that chronically prolonged stress impaired glucocorticoid negative feedback leading to HPA-axis hypoactivity. Since CORT has an ability to inhibit IL-4 production $[22,23,42,43]$ and to increase TH expression [38], chronic stress-induced hypocorticism might reverse the effects produced by acute stress.

Single exposure of stress or lipopolysaccharide has been shown to stimulate release of NE or to increase TH mRNA level and TH activity [17, 51-53]. In contrast with acute stress, TH mRNA level was decreased in a chronic mild stressed group [54]. Since TH is a rate-determining enzyme of NE synthesis, change of TH protein was not detected right after exposure of acute stress [55]. Stress also has shown to increase $\mathrm{TH}$ immunoreactivity, which is consequence of enhanced enzyme activity and $\mathrm{TH}$ protein concentration [56]. In the present study, acute IMO induced increase of THimmunoreactivity in the LC, suggesting this increment might be result from increase of enzyme activity.

In conclusion, stress-induced decline of IL-4 concentration from LC neurons may be related to anxiety-like behavior and an inverse relationship exists between IL- 4 secretion and HPA/SAM-axes activation. These data suggest that modulation of these signaling factors, cytokine, catecholamine, and CORT is required to adapt to homeostatic mechanisms in response to stressful events. 


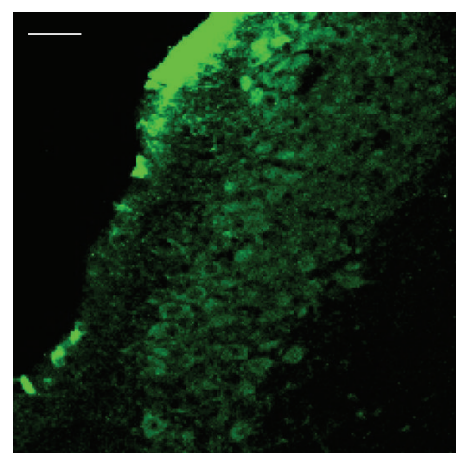

(a)

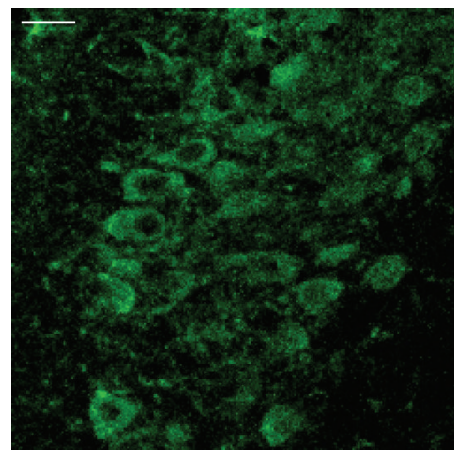

(d)

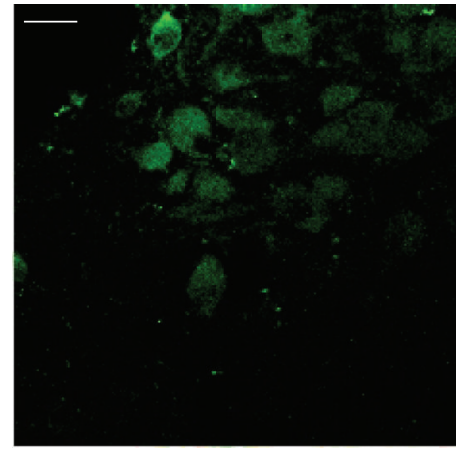

(g)

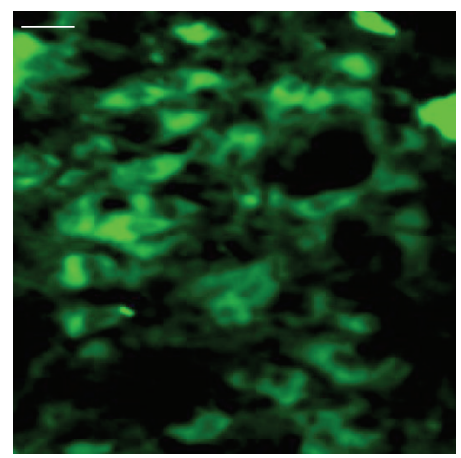

(j)

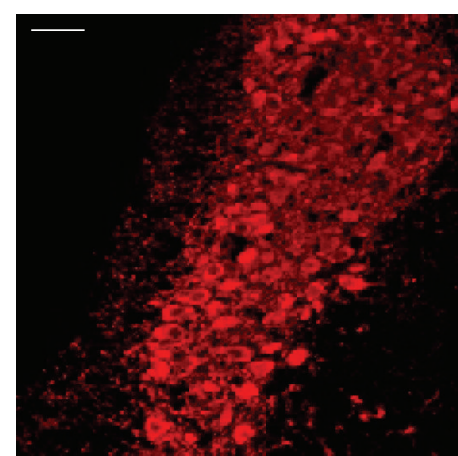

(b)

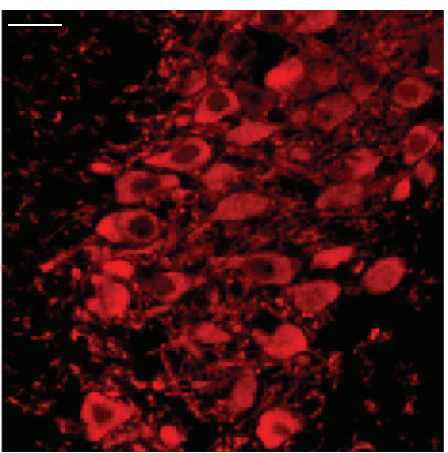

(e)

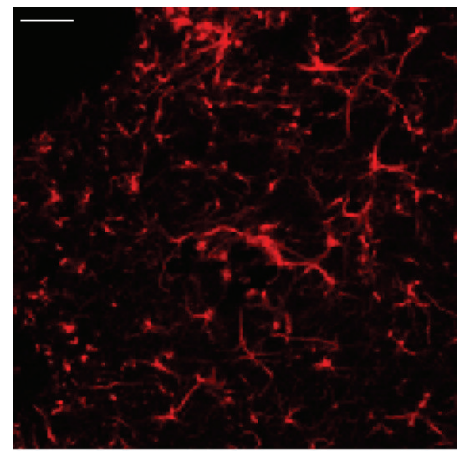

(h)

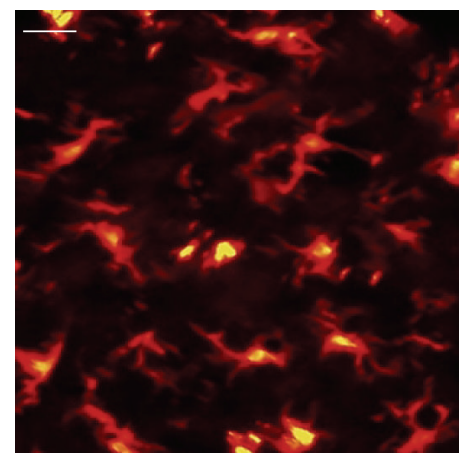

(k)

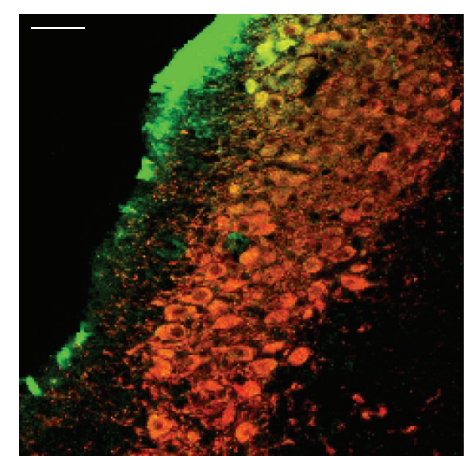

(c)

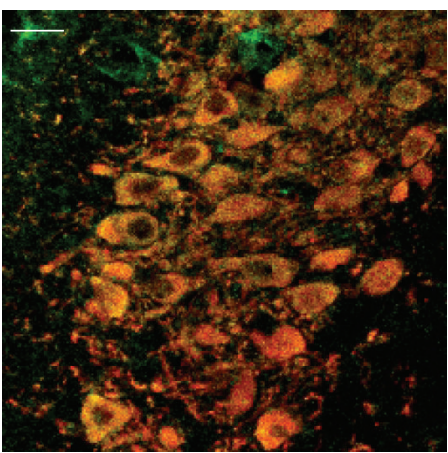

(f)

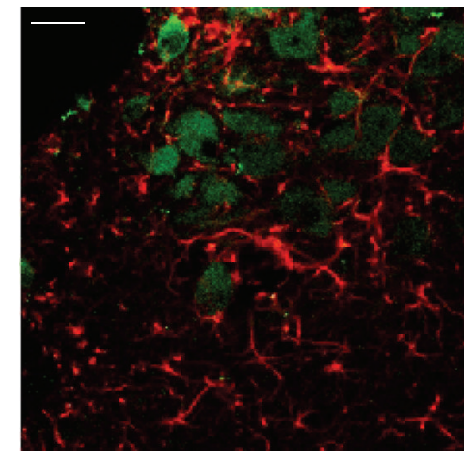

(i)

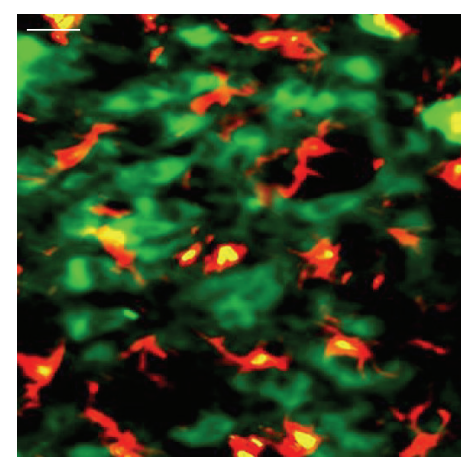

(1)

FIGURE 4: Characterization of IL-4-producing cells in the LC. (a-c) Representative fluorescent images showed that IL-4-secreting cells (a) were colocalized (c) with TH-releasing cells (b). Photomicrographs were taken at $\times 200$ magnification. Scale bars $=50 \mu \mathrm{m}$. $(\mathrm{d}-\mathrm{f})$ High power (taken at $\times 400$ magnification) photographs of (a), (b), and (c), respectively, are shown. Scale bars $=20 \mu \mathrm{m}$. IL-4-releasing cells (g and j) were not merged ( $\mathrm{i}$ and $\mathrm{l}$ ) with GFAP-positive cells (h) or Iba-1-immunoreactive cells (k). Photomicrographs were taken at $\times 400$ magnification. Scale bars $=20 \mu \mathrm{m}$. 


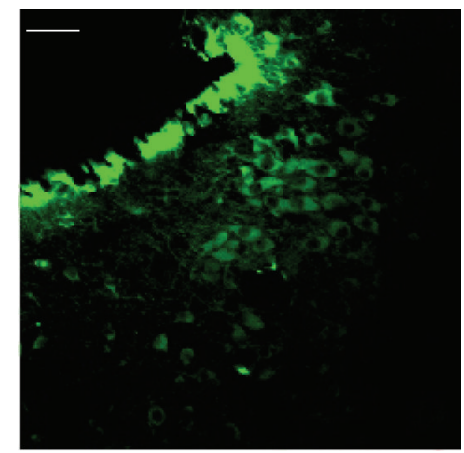

(a)

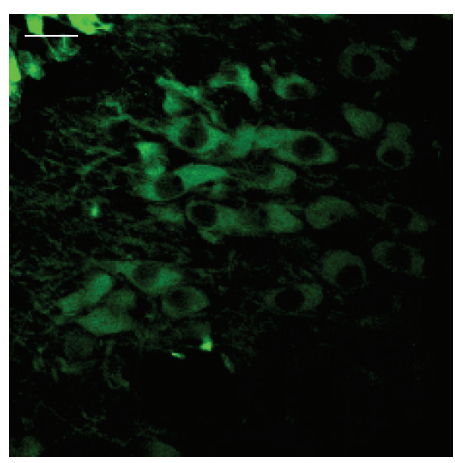

(d)

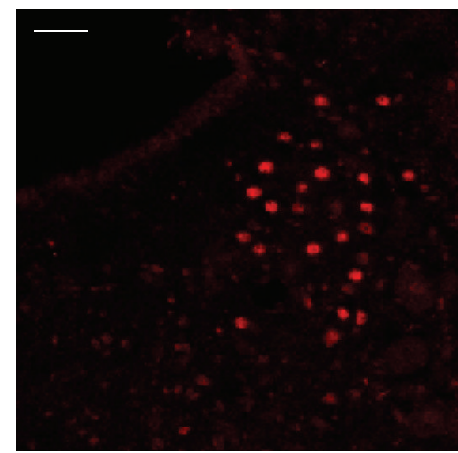

(b)

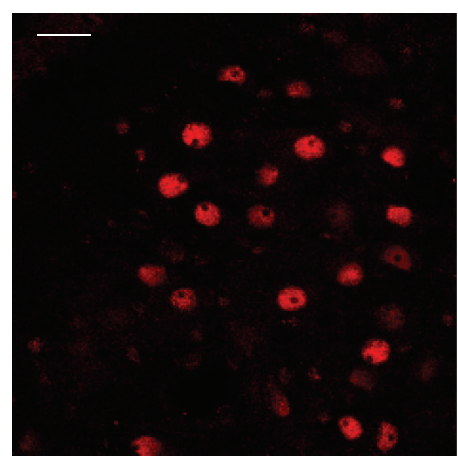

(e)

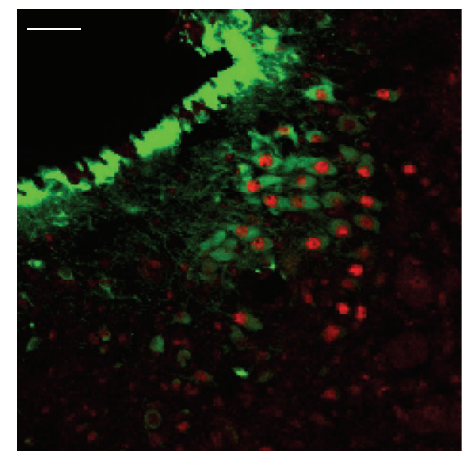

(c)

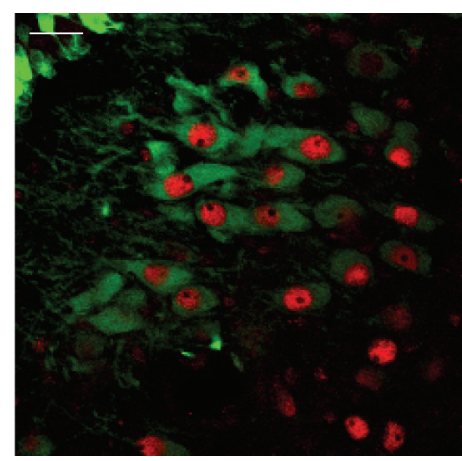

(f)

FIGURE 5: Localization of IL-4 and GR in the LC. (a-c) Representative fluorescent images showed that IL-4 (a) and GR (b) were expressed in the neurons but not in the identical part (c). Photomicrographs were taken at $\times 200$ magnification. Scale bars $=50 \mu \mathrm{m}$. $(\mathrm{d}-\mathrm{f})$ High power (taken at $\times 400$ magnification) photographs of (a), (b), and (c), respectively, are shown. Scale bars $=20 \mu \mathrm{m}$.

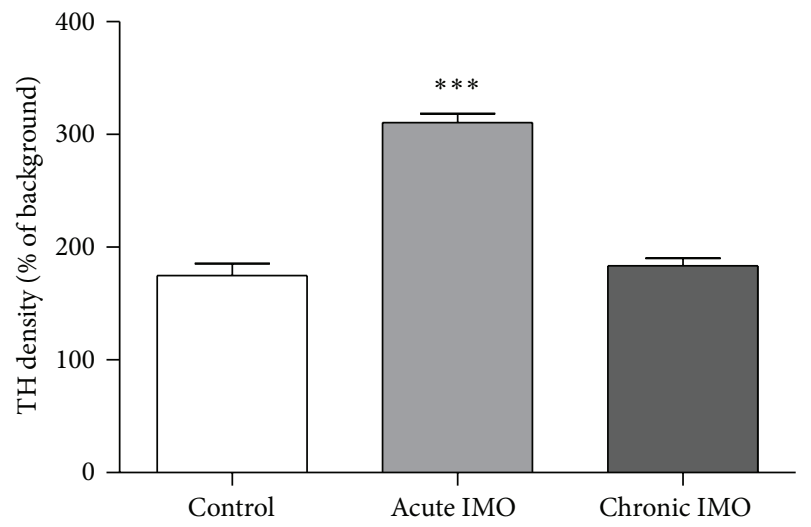

FIGURE 6: Mean ( \pm SEM) quantification of TH expression in the LC of the control group and groups subjected acute and chronic IMO. Acutely stressed rat expressed significantly increase in TH density whereas chronically stressed animals showed no change. $(n=4-5$ per group) ${ }^{* * *} P<0.001$ versus control; ANOVA.
HPA-axis: Hypothalamic-pituitary-adrenal-axis

IMO: Immobilization

IL-4: Interleukin-4

LPS: $\quad$ Lipopolysaccharide

LC: $\quad$ Locus coeruleus

NE: $\quad$ Norepinephrine

SAM-axis: Sympathetic-adrenal-medullary-axis

TH: $\quad$ Tyrosine hydroxylase.

\section{Disclosure}

The current affiliation for Angela Starkweather is Center for Advancement for Managing Pain, School of Nursing, University of Connecticut, CT 06269, USA.

\section{Conflict of Interests}

The authors declare no conflict of interests.

\section{Authors' Contribution}

Hyun-ju Lee and Hyun-Jung Park conducted the animal experiment and analyzed the data. Insop Shim, Angela Starkweather, Kyungeh An, and Hyun-ju Lee participated in design of the study and preparation of the paper. All the 
authors read and approved the final paper. Hyun-ju Lee and Hyun-Jung Park equally contributed to this work.

\section{Acknowledgment}

This research was supported by a National Research Foundation of Korea (NRF) grant funded by the Korean government (Ministry of Education, Science and Technology, MEST) (2006-2005240 and 2013R1A2A2A03069127).

\section{References}

[1] P. H. Black, "Stress and the inflammatory response: a review of neurogenic inflammation," Brain, Behavior, and Immunity, vol. 16, no. 6, pp. 622-653, 2002.

[2] A. Buske-Kirschbaum, S. Kern, M. Ebrecht, and D. H. Hellhammer, "Altered distribution of leukocyte subsets and cytokine production in response to acute psychosocial stress in patients with psoriasis vulgaris," Brain, Behavior, and Immunity, vol. 21, no. 1, pp. 92-99, 2007.

[3] R. Glaser and J. K. Kiecolt-Glaser, "Stress-induced immune dysfunction: implications for health," Nature Reviews Immunology, vol. 5, no. 3, pp. 243-251, 2005.

[4] Y. Nolan, F. O. Maher, D. S. Martin et al., "Role of interleukin4 in regulation of age-related inflammatory changes in the hippocampus," The Journal of Biological Chemistry, vol. 280, no. 10, pp. 9354-9362, 2005.

[5] H. L. Wong, G. L. Costa, M. T. Lotze, and S. M. Wahl, "Interleukin (IL) 4 differentially regulates monocyte IL-1 family gene expression and synthesis in vitro and in vivo," The Journal of Experimental Medicine, vol. 177, no. 3, pp. 775-781, 1993.

[6] Y. Lu, M. Liu, S. Shi et al., "Effects of stress in early life on immune functions in rats with asthma and the effects of music therapy," Journal of Asthma, vol. 47, no. 5, pp. 526-531, 2010.

[7] S. S. Pertsov, E. V. Koplik, V. L. Stepanyuk, and A. S. Simbirtsev, "Blood cytokines in rats with various behavioral characteristics during emotional stress and treatment with interleukin-1 $\beta$," Bulletin of Experimental Biology and Medicine, vol. 148, no. 2, pp. 196-199, 2009.

[8] R. Almeida-Reis, A. C. Toledo, F. G. Reis et al., "Repeated stress reduces mucociliary clearance in animals with chronic allergic airway inflammation," Respiratory Physiology and Neurobiology, vol. 173, no. 1, pp. 79-85, 2010.

[9] K. D. Ackerman, M. Martino, R. Heyman, N. M. Moyna, and B. S. Rabin, "Stressor-induced alteration of cytokine production in multiple sclerosis patients and controls," Psychosomatic Medicine, vol. 60, no. 4, pp. 484-491, 1998.

[10] R. Jacobs, C. R. Pawlak, E. Mikeska et al., "Systemic lupus erythematosus and rheumatoid arthritis patients differ from healthy controls in their cytokine pattern after stress exposure," Rheumatology, vol. 40, no. 8, pp. 868-875, 2001.

[11] T. R. Mosmann and R. L. Coffman, "TH1 and TH2 cells: different patterns of lymphokine secretion lead to different functional properties," Annual Review of Immunology, vol. 7, pp. 145-173, 1989.

[12] K. W. Park, D. Y. Lee, E. H. Joe, S. U. Kim, and B. K. Jin, "Neuroprotective role of microglia expressing interleukin-4," Journal of Neuroscience Research, vol. 81, no. 3, pp. 397-402, 2005.
[13] M. E. Bauer, P. Perks, S. L. Lightman, and N. Shanks, "Restraint stress is associated with changes in glucocorticoid immunoregulation," Physiology and Behavior, vol. 73, no. 4, pp. 525-532, 2001.

[14] T. Buynitsky and D. I. Mostofsky, "Restraint stress in biobehavioral research: recent developments," Neuroscience and Biobehavioral Reviews, vol. 33, no. 7, pp. 1089-1098, 2009.

[15] S. Dal-Zotto, O. Martí, and A. Armario, "Glucocorticoids are involved in the long-term effects of a single immobilization stress on the hypothalamic-pituitary-adrenal axis," Psychoneuroendocrinology, vol. 28, no. 8, pp. 992-1009, 2003.

[16] X. Belda, C. Márquez, and A. Armario, "Long-term effects of a single exposure to stress in adult rats on behavior and hypothalamic-pituitary-adrenal responsiveness: comparison of two outbred rat strains," Behavioural Brain Research, vol. 154, no. 2, pp. 399-408, 2004.

[17] S. Dronjak, L. Gavrilović, D. Filipović, and M. B. Radojčić, "Immobilization and cold stress affect sympatho-adrenomedullary system and pituitary-adrenocortical axis of rats exposed to long-term isolation and crowding," Physiology and Behavior, vol. 81, no. 3, pp. 409-415, 2004.

[18] Y. Watanabe, C. R. McKittrick, D. C. Blanchard, R. J. Blanchard, B. S. McEwen, and R. R. Sakai, "Effects of chronic social stress on tyrosine hydroxylase mRNA and protein levels," Molecular Brain Research, vol. 32, no. 1, pp. 176-180, 1995.

[19] J. P. Herman and W. E. Cullinan, "Neurocircuitry of stress: central control of the hypothalamo-pituitary-adrenocortical axis," Trends in Neurosciences, vol. 20, no. 2, pp. 78-84, 1997.

[20] Y. Joo, K. M. Choi, Y. H. Lee et al., "Chronic immobilization stress induces anxiety- and depression-like behaviors and decreases transthyretin in the mouse cortex," Neuroscience Letters, vol. 461, no. 2, pp. 121-125, 2009.

[21] J. D. Ruys, S. P. Mendoza, J. P. Capitanio, and W. A. Mason, "Behavioral and physiological adaptation to repeated chair restraint in rhesus macaques," Physiology and Behavior, vol. 82, no. 2-3, pp. 205-213, 2004.

[22] E.-Y. So, S.-H. Kim, B.-S. Cho, H.-H. Park, and C.-E. Lee, "Corticosteroid inhibits IL-4 signaling through down-regulation of IL-4 receptor and STAT6 activity," FEBS Letters, vol. 518, no. 1-3, pp. 53-59, 2002.

[23] S. P. Umland, D. K. Nahrebne, S. Razac et al., "The inhibitory effects of topically active glucocorticoids on IL-4, IL- 5, and interferon- $\gamma$ production by cultured primary $\mathrm{CD} 4^{+} \mathrm{T}$ cells," Journal of Allergy and Clinical Immunology, vol. 100, no. 4, pp. 511-519, 1997.

[24] S. S. Pertsov, E. V. Koplik, and L. S. Kalinichenko, "Modulating effect of interleukin- 4 on free radical processes in the brain of rats during emotional stress," Bulletin of Experimental Biology and Medicine, vol. 151, no. 4, pp. 396-399, 2011.

[25] A. A. Walf and C. A. Frye, "The use of the elevated plus maze as an assay of anxiety-related behavior in rodents," Nature Protocols, vol. 2, no. 2, pp. 322-328, 2007.

[26] V. M. Pickel, T. H. Joh, and D. J. Reis, "Ultrastructural localization of tyrosine hydroxylase in noradrenergic neurons of brain," Proceedings of the National Academy of Sciences of the United States of America, vol. 72, no. 2, pp. 659-663, 1975.

[27] G. Paxinos, C. Watson, M. Pennisi, and A. Topple, "Bregma, lambda and the interaural midpoint in stereotaxic surgery with rats of different sex, strain and weight," Journal of Neuroscience Methods, vol. 13, no. 2, pp. 139-143, 1985.

[28] D.-H. Kang and C. Fox, "Th1 and Th2 cytokine responses to academic stress," Research in Nursing and Health, vol. 24, no. 4, pp. 245-257, 2001. 
[29] M. L. Peters, G. L. R. Godaert, R. E. Ballieux et al., "Immune responses to experimental stress: effects of mental effort and uncontrollability," Psychosomatic Medicine, vol. 61, no. 4, pp. 513-524, 1999.

[30] R. Vig, J. R. Gordon, B. Thébaud, A. D. Befus, and H. Vliagoftis, "The effect of early-life stress on airway inflammation in adult mice," Neuroimmunomodulation, vol. 17, no. 4, pp. 229-239, 2010.

[31] E. J. Downer, T. R. Cowley, A. Lyons et al., "A novel antiinflammatory role of NCAM-derived mimetic peptide, FGL," Neurobiology of Aging, vol. 31, no. 1, pp. 118-128, 2010.

[32] A. Lyons, K. McQuillan, B. F. Deighan et al., "Decreased neuronal CD200 expression in IL-4-deficient mice results in increased neuroinflammation in response to lipopolysaccharide," Brain, Behavior, and Immunity, vol. 23, no. 7, pp. 10201027, 2009.

[33] M. Maes, C. Song, A. Lin et al., "The effects of psychological stress on humans: increased production of pro-inflammatory cytokines and a Th1-like response in stress-induced anxiety," Cytokine, vol. 10, no. 4, pp. 313-318, 1998.

[34] F. Missima, A. C. Pagliarone, C. L. Orsatti, J. P. Araújo Jr., and J. M. Sforcin, "The Effect of propolis on Th1/Th2 cytokine expression and production by melanoma-bearing mice submitted to stress," Phytotherapy Research, vol. 24, no. 10, pp. 1501-1507, 2010.

[35] C. Chotiwat and R. B. S. Harris, "Increased anxiety-like behavior during the post-stress period in mice exposed to repeated restraint stress," Hormones and Behavior, vol. 50, no. 3, pp. 489495, 2006.

[36] G. H. Gameiro, P. H. Gameiro, A. da Silva Andrade et al., "Nociception- and anxiety-like behavior in rats submitted to different periods of restraint stress," Physiology and Behavior, vol. 87, no. 4, pp. 643-649, 2006.

[37] S. Sevgi, M. Özek, and L. Eroğlu, "L-NAME prevents anxietylike and depression-like behavior in rats exposed to restraint stress," Methods and Findings in Experimental and Clinical Pharmacology, vol. 28, no. 2, pp. 95-99, 2006.

[38] B. Lee, B. Sur, M. Yeom, I. Shim, H. Lee, and D.-H. Hahm, "Alpha-asarone, a major component of Acorus gramineus, attenuates corticosterone-induced anxiety-like behaviours via modulating TrkB signaling process," Korean Journal of Physiology and Pharmacology, vol. 18, no. 3, 2014.

[39] R.-M. Bluthé, J. Lestage, G. Rees, A. Bristow, and R. Dantzer, "Dual effect of central injection of recombinant rat interleukin4 on lipopolysaccharide-induced sickness behavior in rats," Neuropsychopharmacology, vol. 26, no. 1, pp. 86-93, 2002.

[40] C. L. Sherry, S. S. Kim, R. N. Dilger et al., "Sickness behavior induced by endotoxin can be mitigated by the dietary soluble fiber, pectin, through up-regulation of IL- 4 and Th2 polarization," Brain, Behavior, and Immunity, vol. 24, no. 4, pp. 631-640, 2010.

[41] M. L. Moon, J. J. Joesting, N. A. Blevins et al., "IL-4 knock out mice display anxiety-like behavior," Behavior Genetics, vol. 45, no. 4, pp. 451-460, 2015.

[42] D. Schmidt, S. O. Reber, C. Botteron et al., "Chronic psychosocial stress promotes systemic immune activation and the development of inflammatory Th cell responses," Brain, Behavior, and Immunity, vol. 24, no. 7, pp. 1097-1104, 2010.

[43] E. D. Stanulis, S. D. Jordan, J. A. Rosecrans, and M. P. Holsapple, "Disruption of Th1/Th2 cytokine balance by cocaine is mediated by corticosterone," Immunopharmacology, vol. 37, no. 1, pp. 2533, 1997.
[44] A. Cintra, M. Zoli, L. Rosén et al., "Mapping and computer assisted morphometry and microdensitometry of glucocorticoid receptor immunoreactive neurons and glial cells in the rat central nervous system," Neuroscience, vol. 62, no. 3, pp. 843897, 1994.

[45] M.-S. Lee, Y.-H. Kim, W.-S. Park et al., “Temporal variability of glucocorticoid receptor activity is functionally important for the therapeutic action of fluoxetine in the hippocampus," Molecular Psychiatry, 2014.

[46] A. García, O. Martía, A. Vallès, S. Dal-Zotto, and A. Armario, "Recovery of the hypothalamic-pituitary-adrenal response to stress. Effect of stress intensity, stress duration and previous stress exposure," Neuroendocrinology, vol. 72, no. 2, pp. 114-125, 2000.

[47] M. Adzic, J. Djordjevic, A. Djordjevic et al., "Acute or chronic stress induce cell compartment-specific phosphorylation of glucocorticoid receptor and alter its transcriptional activity in Wistar rat brain," Journal of Endocrinology, vol. 202, no. 1, pp. 87-97, 2009.

[48] A. Djordjevic, M. Adzic, J. Djordjevic, and M. B. Radojcic, "Stress type dependence of expression and cytoplasmic-nuclear partitioning of glucocorticoid receptor, Hsp90 and Hsp70 in Wistar rat brain," Neuropsychobiology, vol. 59, no. 4, pp. 213-221, 2009.

[49] O. Malkesman, R. Maayan, A. Weizman, and A. Weller, "Aggressive behavior and HPA axis hormones after social isolation in adult rats of two different genetic animal models for depression," Behavioural Brain Research, vol. 175, no. 2, pp. 408-414, 2006.

[50] M. Sánchez, F. Aguado, F. Sánchez-Toscano, and D. Saphier, "Neuroendocrine and immunocytochemical demonstrations of decreased hypothalamo-pituitary-adrenal axis responsiveness to restraint stress after long-term social isolation," Endocrinology, vol. 139, no. 2, pp. 579-587, 1998.

[51] S. A. Sands, R. Strong, J. Corbitt, and D. A. Morilak, "Effects of acute restraint stress on tyrosine hydroxylase mRNA expression in locus coeruleus of Wistar and Wistar-Kyoto rats," Molecular Brain Research, vol. 75, no. 1, pp. 1-7, 2000.

[52] M. Prieto, F. M. Gómez, and M. T. Giralt, "Effects of acute, repeated and chronic variable stress on in vivo tyrosine hydroxylase activity and on $\alpha^{2}$-adrenoceptor sensitivity in the rat brain," Stress, vol. 6, no. 4, pp. 281-287, 2003.

[53] L. K. Ong, L. Sominsky, P. W. Dickson, D. M. Hodgson, and P. R. Dunkley, "The sustained phase of tyrosine hydroxylase activation in vivo," Neurochemical Research, vol. 37, no. 9, pp. 1938-1943, 2012.

[54] R. Dunčko, A. Kiss, I. Škultétyová, M. Rusnák, and D. Ježová, "Corticotropin-releasing hormone mRNA levels in response to chronic mild stress rise in male but not in female rats while tyrosine hydroxylase mRNA levels decrease in both sexes," Psychoneuroendocrinology, vol. 26, no. 1, pp. 77-89, 2001.

[55] L. K. Ong, L. Guan, B. Stutz, P. W. Dickson, P. R. Dunkley, and L. Bobrovskaya, "The effects of footshock and immobilization stress on tyrosine hydroxylase phosphorylation in the rat locus coeruleus and adrenal gland," Neuroscience, vol. 192, pp. 20-27, 2011.

[56] M. J. Zigmond, J. M. Finlay, and A. F. Sved, "Neurochemical studies of central noradrenergic responses to acute and chronic stress-implications for normal and abnormal behavior," in Neurobiological and Clinical Consequences of Stress-From Normal Adaptation to Post-Traumatic Stress Disorder, M. J. Friedman, D. S. Charney, and A. Y. Deutch, Eds., chapter 3, pp. 45-60, Lippincott-Raven Publishers, Philadelphia, Pa, USA, 1995. 


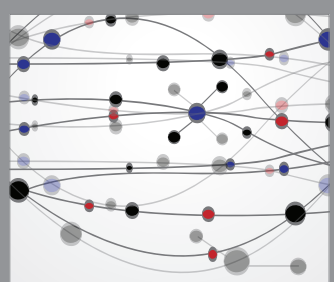

The Scientific World Journal
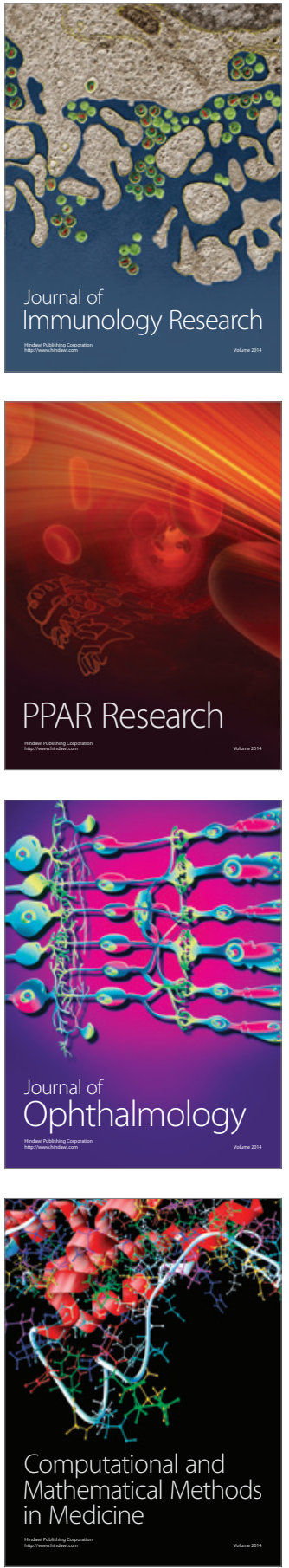

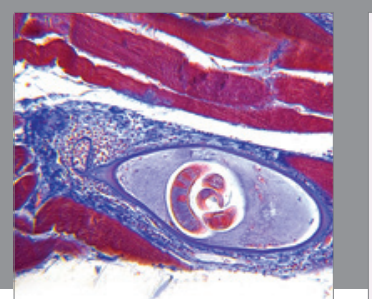

Gastroenterology Research and Practice

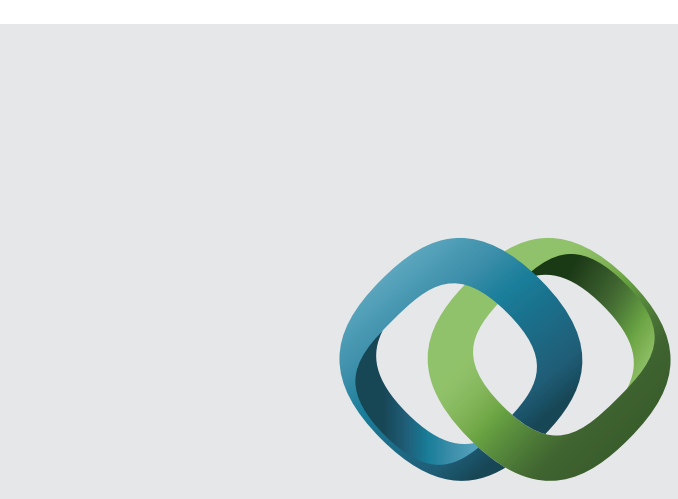

\section{Hindawi}

Submit your manuscripts at

http://www.hindawi.com
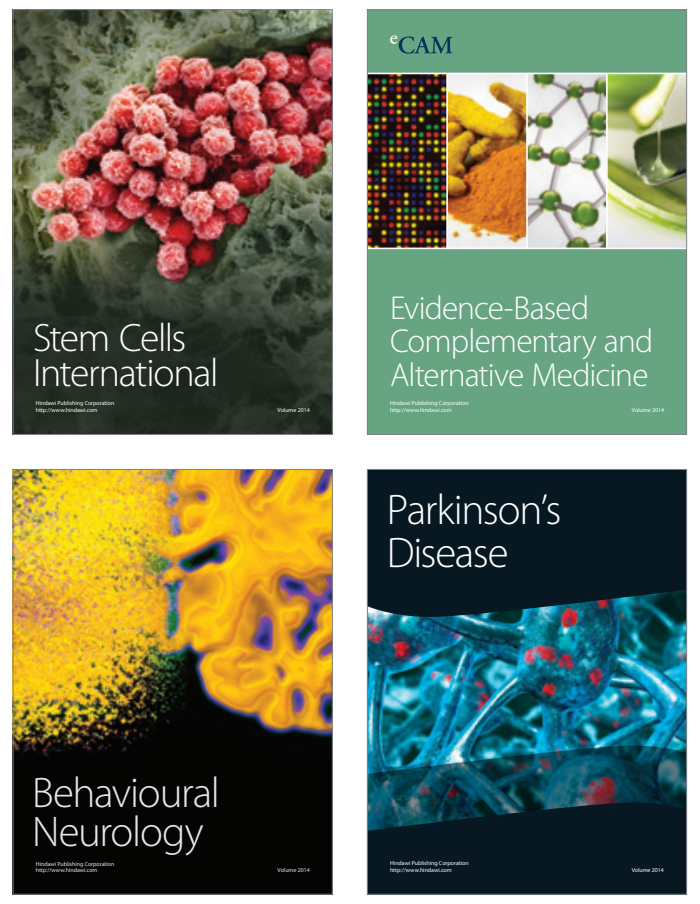
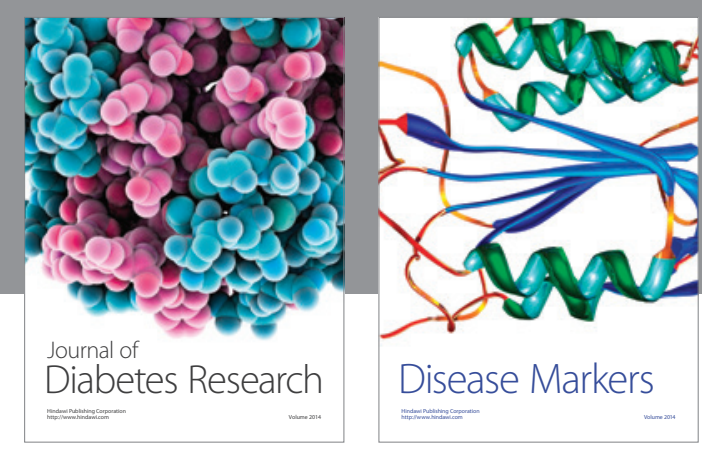

Disease Markers
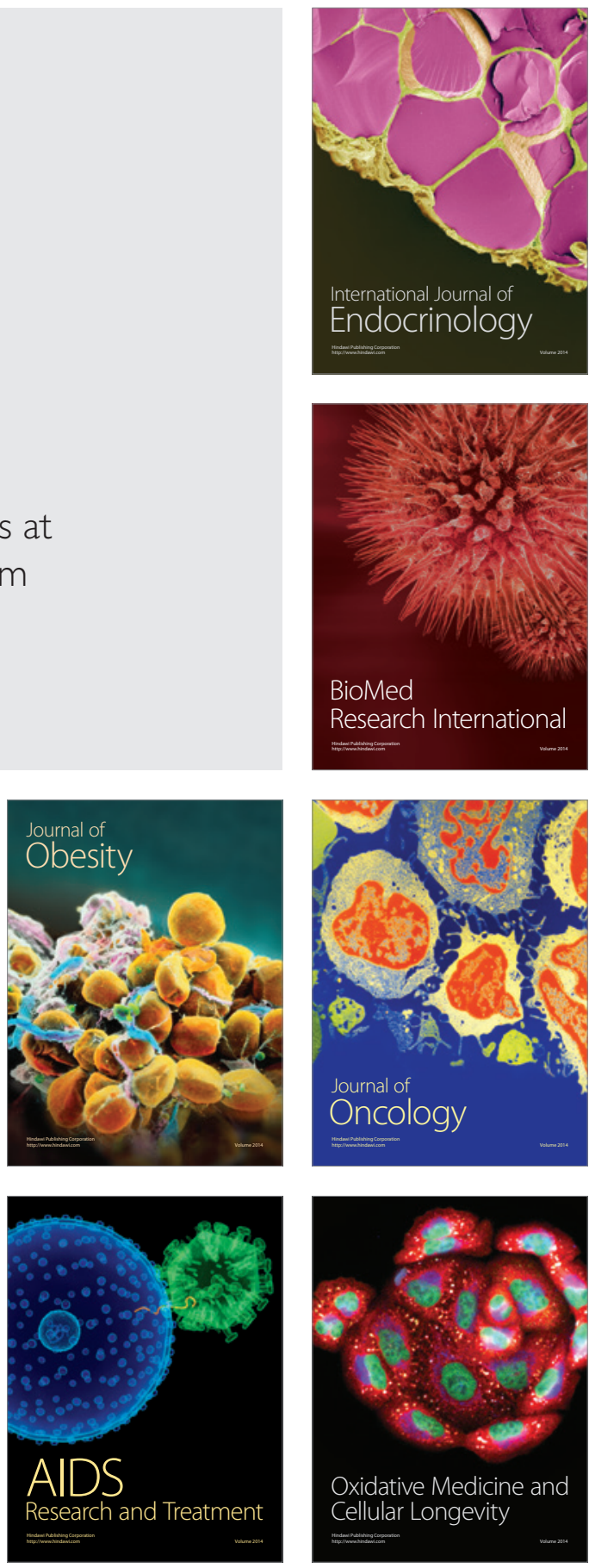